\title{
Internationalizing Education: Critical Qualitative Case Studies in Social Education
}

\author{
Cameron White* \\ University of Houston, Farish Hall, Houston, TexaS \\ *Corresponding author: cswhite@uh.edu \\ Received January 15, 2015; Revised February 06, 2015; Accepted February 10, 2015

\begin{abstract}
The article addresses the need to integrate critical qualitative research in social education. In a world increasingly dominated by globalization and privatization, critical investigation of local to global issues in education are vital. Case studies of internationalizing efforts in education are described in order to provide a social justice / equity connections. Such educational endeavors facilitate the critical investigation of meaningful knowledge and issues, debates regarding globalization, and relevant problem-based global education that can provide the context for developing the skills engage in active transformation for social justice.
\end{abstract}

Keywords: international education, critical qualitative research, social education / social justice

Cite This Article: Cameron White, "Internationalizing Education: Critical Qualitative Case Studies in Social Education.” American Journal of Educational Research, vol. 3, no. 2 (2015): 211-219. doi: 10.12691/education$3-2-15$.

\section{Internationalizing Education through Critical Qualitative Research}

Growing up today is very different than even a decade ago. Today the world truly is a smaller place and we really are part of a global neighborhood. People are instantaneously connected to international events through media, technology, trade, and global issues such as conflict, climate, and socio-economics. Borders do not mean the same as they did just a few years ago. A "globalized" world necessitates international connections, thus challenging traditional conceptions of nationalism, exceptionalism, and hegemony.

This piece investigates internationalizing of education through critical case studies, narrative, and self-study and suggests that we need to contextualize the issues and investigation of global connections better. The chapter also suggests there are threats to the public sphere and to emancipatory local to global connections thus requiring critical approaches to such investigations / research. The methods employed offer a variety of perspectives allowing for critical analysis and ultimately transformative ideas. Using such examples provides stories, applications, ideas, and challenges that can hopefully open up the possibilities for additional perspectives to be offered.

Teaching and learning must include education for a global perspective so that students might also become responsible "active" citizens of the world (Tucker \& Evans, 1996; Diaz, Massialas \& Xanthopoulos, 1999; Chapin, 2003). A critical component of education in general, and social education specifically, is to promote an understanding of diversity at home and abroad: “integrating global realities within an existing school curriculum meets the needs of an ever-changing, ethnically diverse, increasingly interdependent, international community" (Tucker \& Evans, 1996). World citizenship requires a global / international education.

Global / international education efforts must begin with an attempt to understand globalization. Globalization can be defined as "the intensification of worldwide social relations which link distant localities in such a way that local happenings are shaped by events occurring many miles away and vice versa” (McLaren, 2001). In turn, critical research in social education attempts to challenge the unbridled neoliberal hegemony associated with globalization. Diaz, Massialas, and Xanthopoulos (1999) state that globalization refers to the compression of the world and to the intensification of the consciousness of the world as a whole. This process is ongoing and all of us, young and old, Westerners and non-Westerners, are inescapably involved in it. The compression of the world is real. People witness it in their daily lives, in the foods they eat, in the TV programs they watch, in the cars they drive, in the dresses and costumes, in the people they choose to govern them, and so on (pp. 37-38).

Clearly, globalization is increasingly influential in most aspects of 21st century life. Therefore understanding it through global / international education is imperative. Schools must provide opportunities for children to "develop the appropriate cognitive skills to understand and explain the globalization process and to critically analyze its impact on their lives and the lives of people around them" (Diaz, Massialas \& Xanthopoulos, 1999, p. 38). Above all students need to know how to impact the global system as world citizens and as advocates of a wellgrounded position or point of view. This suggests that students must acquire both a new knowledge base and a skill set. Many of the subjects associated with social 
studies might offer an appropriate space for global education - but other disciplines are ripe for integration as well. At its core, global education is really about analyzing the links between cultures and people (Chapin, 2003); it must be better integrated in all classrooms, and thus critically researched as well.

Rethinking teaching and learning in these ways could provide the opportunity to deepen our understanding and appreciation of others in the world, something essential to our roles and responsibilities as global citizens. Given the global interconnectedness of the world today, the global context must be present. According to Merryfield (2001), students must develop a global perspective that will emphasize cross-cultural experiential learning and stress commonalities in cultures that transcend diversity.

Increased globalization presents many challenges for societies and the institution of education has a responsibility for addressing these "globalized" issues. Education in general should play a strong role and is enhanced through internationalizing partnerships and projects. In addition, cultural competence, collaboration skills, and an appreciation of global connections can be facilitated through cross-cultural experiences in teacher education, thus translating to the classroom. Many schools, colleges and universities are recognizing the need for global competence and promoting understanding among cultures (Dan-xia, 2008). In addition, linking multicultural education and global issues is facilitated through meaningful international education projects (Wells, 2008). James suggests that internationalizing education develops a sense of interconnectedness, empathy, and tolerance, which are much needed in today's world (2005). Education programs have much work to do to accomplish these ideas. A way to move forward is to share ideas and engage in collaborative internationalizing of the curriculum.

Schools in the United States must provide opportunities for students to learn about the world: who people are, what they do, and how they live. Students must learn how to get along with all people - within the U.S. and around the world - as responsible citizens of both. Education for civic competence, for responsible national and world citizenship, falls within the domain of social studies instruction and learning. We must rethink teaching and learning so as to enable these ideas. Integrating music, movies, art, and literature focusing on global issues or celebrating global culture offers a great opportunity; thus enabling many opportunities for critical qualitative research projects.

Fortunately, increased and improved research on internationalizing is being undertaken at many levels of education. In addition, numerous international education experiences focusing on study trips, consulting, teaching and research have contributed to this "new found" interest. Our critical qualitative approach suggests that educators at all levels must be engaged in collaborative research, teaching, and service (Herr \& Anderson, 2005). Critical qualitative educational research highlights the need to cultivate knowledge, skills, and dispositions for global and civic awareness and responsibility (Loewen, 2007; OchoaBecker, 2006; Ross, 2006). Additionally, to be engaged, global citizens, students need exposure to multiple literacies and diverse perspectives (Durham \& Kellner, 2005; Giroux, 2006; Silberman-Keller, 2008).

\section{Social Education, Social Justice and Educational Research}

Critical qualitative research informs social education through a lens that ensures the investigation of issues in education tied to power and privilege, ultimately leading to advocacy and activism. The concept of critical is increasingly challenged in this age of neoliberal reform; nevertheless, critical implies questioning, investigating and challenging in terms of equity and social justice, leading to critical consciousness (Freire, 1970). While we resist defining social education, as hopefully these ideas / concepts are fluid, the idea stems from a continual analysis and synthesis of critical theory/ critical pedagogy, media and cultural studies, social reconstruction / social justice, and social studies education framed by culturally responsive pedagogy. A social education take on critical qualitative research thus suggests multiple truths and perspectives and focuses on questions rather than answers.

While many have written on qualitative educational research and some have attempted to integrate critical pedagogy and qualitative research, few have explored the specific idea of social education and critical qualitative research. A major issue is that social education claims that there are no set procedures, scripted approaches, or narrow definitions as to the possibilities of research endeavors. Social education researchers make the process and investigation their own and adapt questions, procedures, methods, and strategies throughout the experience. The reflects an ever changing criticality in the bricolage of the research (Steinberg, 2011).

A "schism" of sorts is still perpetuated by the either / or debate regarding the efficacy of quantitative / qualitative or even mixed methods approaches to educational research. The claim here is that humanity cannot and should not be continually subjected to quantification - that it reduces human endeavor to meaningless claims in the guise of objectivity. A particular argument made in social education is that education and U.S. society in general is so dominated by a positivist, quantitative framing that often impedes educational progress. Therefore, we adamantly argue that in doing social education one must focus on critical qualitative research almost exclusively.

Social education is interested in empowering the disempowered, so that education and schooling should be about addressing societal issues tied to race, ethnicity, gender, age, and orientation. When we have a society that continues to struggle with mass incarceration, gun violence, lack of voting rights, $19^{\text {th }}$ century immigration policy, entitlements to the military, corporations, and the rich, perpetual war, and non-stop imperialism, then societal transformation can be the only goal. In other words, a particular critique made by social educators is that humanity and efficacy have been divorced from education.

Many great educators, theorists, and philosophers serve as the grounding for critical qualitative research through a social education perspective. Marx and Dewey are perhaps the most important theorists as they provide the foundations for most everything since. A second wave includes the likes of Gramsci, Freire, Green, Apple, Giroux, and McLaren. Still more include Zinn, Kozol, Banks, hooks, Noddings, Nieto, Sleeter, and Duncan- 
Andrade. Each of these, and many others, are vital for any social education literature analysis.

As Kincheloe, McLaren and Steinberg (2012) state, a form of social or cultural criticism is the basis of such research. They go on to suggest seven assumptions in critical qualitative research in social education:

1. Social and historically constructed power issues affect all human endeavor;

2. Ideology and value judgments knowledge, skills, and dispositions;

3. Capitalism affects the construction of individual and group process / products;

4. Objectivity is a myth and that language and culture necessitate subjectivity;

5. Privilege and oppression are rampant and critical consciousness is a primary focus;

6. Traditional and mainstream practice contribute to reproduction of issues tied to equity and social justice.

These assumptions are address at least globally within this chapter. Nevertheless, the argument herein is that all education is or should be social education. We are all social "human" beings struggling to develop knowledge, skills, and dispositions through lifelong education, both in and out of "school" in order to make the best of life, hopefully for ourselves and others.

\section{Pillars of Social Education}

There are five broad pillars or themes that comprise social education. These include Social Reconstruction / Social Justice, Critical Theory/ Critical Pedagogy, Media / Cultural Studies, Social Studies / History Education, and Culturally Responsive / Multiple Perspectives. Each of these have contributed to a transformation from traditional social studies education approaches to teaching and learning, curriculum and instruction to one that is first critical in the sense that deconstruction and multiple truths are championed with the hope for emancipatory education practice. This is turn will also hopefully lead to challenges to the current neoliberal, privatized and globalized "vision" / direction of much within education. The idea is that the public sphere remains the place where the true potential for human transformations can take place (Giroux, 2004).

Social Education stems from a social reconstructionist / social justice philosophical foundation. The idea suggests that democracy and capitalism are antithetical and that unbridled capitalism has usurped democratic practice (Apple, 1990). Equity and social justice need be the ultimate goal of any education endeavor focusing on race, ethnicity, gender, orientation, age, and ability when addressing any social issue; and thus should be prevalent in any critical qualitative research. Rethinking, reconceptualizing, and restructuring schooling, education, curriculum and instruction is stressed if we are truly interested in equity and meeting basic human needs (McLaren, 2003). An issue and problem based approach to research is also warranted.

Critical theory / critical pedagogy take the social justice / social reconstructionist pillar and apply it as praxis in education. Specific education practices that do not deal with issues of power and privilege are subject to challenge. Investigating the human story champions subjectivity as it allows for multiple perspectives, deeper inquiry, and critical endeavor. The assumption is that most human endeavor, especially in education is political, and that we must accept this and understand these issues and deal with the biases and issues inherent in the political nature of things. Education must always be aware and engage in the struggle for social justice in addressing issues of race, ethnicity, gender, age, orientation, perspective, and basic rights and responsibilities in this age of neoliberal reform (Kinceloe, 2008).

Media and cultural studies assumes that art and culture are central to humanity and that each struggles with the assumed public / private binary. Increased commodification and assimilation of media and culture through globalized impositions warrant critical investigation in education, as media and culture greatly influence human interactions. Media is a powerful entity in the education process and also in impacting individual and group identity - thus the need for critical media "literacy." Linking cultural studies is vital in that culture is the result of human interaction and progress with issues of acculturation and assimilation constantly affecting society. Social education claims media and culture are primary texts for critical qualitative research (White \& Walker, 2008).

Social studies / history education is the content tradition whereby social education stems. Knowledge, skills, and dispositions gained from one's social studies and history education experience should facilitate rights and responsibilities of local - global citizenship. Social education suggest that traditionally social studies and history education have served the status quo in that a grand narrative has often been imparted leading to ethnocentrism, exceptionalism, imperialism, and a challenge to the public good (Zinn, 2005; Loewen, 2007). A critical investigation of social studies history education thus brings to light issues of equity, power, privilege, hegemony and social justice.

Culturally responsive / multiple perspectives are linked to critical pedagogy and social justice issue in that curriculum and instruction has often been limited to white privilege, power and lack of choice. Social education insists that education focus on being responsive to culture (in the broad conception of the term) and allow multiple perspectives so as to awaken an appreciation and action tied to diversity (Gay, 2010). A critical multiculturalism requires a rethinking of curriculum instruction and ultimately a transformation of schooling (hooks, 1994). Any practice or institution that threatens these should be subject to deep critique and investigation.

\section{Methods}

Critical qualitative research intends to investigate complex "real-life" educational and societal issues in great depth (Steinberg \& Cannealla, 2012). Steinberg (2012) also suggests that such methods highlight humanistic approaches and challenge empiricism and positivism, for example. Critical education research is framed in in a social reconstruction tradition, continually investigating for social justice. The intention is to ensure research that is critically and explicitly grounded in personal and collective experiences - investigating the human condition in an educational context. In order to understand better the 
complexities of education in a culturally responsive context and to engage a local to global framing, a variety of relevant critical qualitative methods are integrated and adapted as need to address questions and issues. In order to record the "experiences, ideas, fears, mistakes, confusions, breakthroughs and problems that arise" narratives are integrated in such research (Connelly \& Clandinin, 1990). These approaches approach is intended to provide a structure, by which we can begin to understand the educational process, linked individual and societal issues, the local to global tensions and, the ways in which theory and practice impact.

Critical qualitative research borrows from many other qualitative research methodologies; however, what distinguishes it from other methodologies is its orientation on the social justice and societal transformation (LaBoskey, 2004; Loughran, 2005; Samaras \& Freese, 2006). Johnston suggests that it is reflective inquiry in the Deweyian sense and should be situated in the "struggles, politics, complexities, and tensions of the context and are not subject to the questions, critique, and validation of others" (Johnston, 2006, p. 62). LaBoskey (2004) suggests four basic features for such research: the first is an aim towards improvement; the second is interaction with colleagues; the third is the use of multiple qualitative methods; and the fourth is to make the work available to the professional community. Criticalists in social education would add that activism and transformation by the ultimate goal. Critical qualitative research in social education calls for an inward and outward look at theory and practice, and should specifically focus on change. Johnston (2006) finds that a focus on taking action and studying the consequences for education is the hallmark of this research. When implemented, triangulation within critical research leads to a richness and celebration of the human endeavor.

Herr and Anderson (2005), when writing about qualitative research, share some of Johnston's ideas. They find that research questions come out of educational theory and practice; they are born from the needs and problems of the context. In making the case for this approach to research Herr and Anderson (2005) write:

It is an account of how researchers / educators went about learning his or her craft and what was learned in the process. Such insider accounts generate important knowledge and questions to be shared, just as other similar methods do. In fact, they begin to build a knowledge base that can inform the research community about the actions and beliefs tied to equity and social justice - a knowledge base that is otherwise difficult to address,/ investigate / discover.

The integration of critical qualitative methods for these research projects is not intended to overly complicate the research. It is intended to provide a structure, by which we can begin to understand ourselves as educators, the integration of an international focus and the ways in which theory and practice impact others. The critical lens is vital in that research questions and methodology are fluid and adapting as research progresses.

Putting the "critical" in qualitative research intends to challenge even traditional approaches to research, including qualitative. Within a social education framework, critical implies consistent exploration and investigation of social issues through a social justice lens.
The idea is that most human endeavor is socially constructed and that both individual and collaborative experiences are needed for us to develop into socially conscious beings focusing on advocacy and activism. Citizenship necessitates awareness first, but most important, critical action allowing for multiple perspectives, questions rather than answers, and ongoing flexibility regarding the mediation of knowledge, skills, and dispositions.

Hickey (2012) suggests several epistemological commandments for critical qualitative research.

1. Demonstrate incredulity toward claims of grand truths or meta-narratives.

2. Resist contexts that marginalize people in any situation.

3. Commit to betterment, assistance, hope, and emancipation in all human experiences.

4. Challenge any practice that marginalizes based on race, ethnicity, gender, orientation, class, age, ability, or belief.

5. Question unbridled capitalism and neoliberalism.

6. Champion multiple perspectives, diversity, and human experiences.

7. Promote advocacy and activism for basic human rights and democracy for all.

8. Continue a lifelong work for societal transformation toward equity and social justice.

\section{Implications for the 21st Century}

Critical qualitative research and social education are vital for the world of the 21st century. The onslaught of neoliberalism, corporatization, standardization, testing, and the continuing attack on public schools and educators necessitate critical approaches to teaching and learning along with critical qualitative research in social education. Ongoing issues with equity and social justice tied to race, ethnicity, class, orientation, age, and ability linking to schooling, education, teaching and learning must be addressed. The struggle between unbridled capitalism and democracy warrant these investigations in the 21st century, hopefully leading to advocacy and activism.

Empowering and emancipating educators and students requires a redesigning of schooling to demonstrate a truly democratic way of life, to be consistent with the ideals of equity and social justice, to be informed by research that is “educative” (Zeichner, 2009). According to Goodman, Ullrich and Nana (2012), a “triple consciousness' based on Freire's critical consciousness is much needed for equity and social justice in a teaching and learning context. We must model critical multicultural, social justice education (culturally responsive pedagogy), work to transform perspectives of all education, society and its stakeholders, and engage in critical emancipatory research leading to advocacy and activism.

We must continually challenge the corporatized, unequal, and essentialist framing of education. Education is both a political and ethical endeavor hoping to facilitate critically active students anxious to engage in the world. Linking the process to the community and the world provides the context we all need to understand and advocate for equity and social justice. A critical qualitative research in social education that investigates 
these hard issues locally and globally can only lead to empowering educators and students as change agents.

\section{Three Internationalizing Projects}

While many current internationalizing research projects might be shared, three projects that implement critical qualitative research strategies in a social education context are discussed here. These projects include Global Classrooms, Internationalizing Curriculum and Instruction, and Internationalizing through China. The projects demonstrate an ongoing internationalizing education project in the Department of Curriculum and Instruction at the University of Houston., a long term effort that demonstrates the needed local to global connections despite little support from leadership.

Global Classrooms is a project focusing on integrating Model UN and local to global contexts through a knowledge, skills, and dispositions framework at local secondary schools. The project is intended to address needs in high needs schools for contextualized social education through the investigation of local / global issues and developing life skills. As a 12 year critical qualitative longitudinal study, many stories emerge regarding student and teacher struggles in schools today, particularly in balancing traditional teaching and learning with integrating a student-centered issues based program that is not included in the standardized testing.

The second project discussed investigates a curriculum and instruction department's internationalizing efforts. The project documents issues and ideas among faculty and stakeholders in dealing with often contradictory impositions from leadership at the college and university level in again linking local to global efforts in education. The project addresses empowerment issues and struggles with bureaucratic business models in addressing global / international issues.

The final project included focuses specifically on China as a case study for internationalizing education efforts. Study abroad and partnership programs linking a college of education with Chinese counterparts are documented. Specific components again address issues with internationalizing, providing local and global contexts, and dealing with the "critical" in such projects.

While additional examples / case studies are available including study abroad, international partnerships, and Fulbright research, these represent a varied approach to internationalizing and to critical qualitative research in social education. They demonstrate the ongoing issues and struggles for qualitative researchers in increasingly neoliberal higher education institutions. To go further with critical approaches in social education only exacerbates the problem confronting research in education - that to challenge and question in the hope of transformation for equity and social justice is often belittled, dismissed, or even denied as contributing to scholarship.

\section{Global Classrooms}

The uniqueness of Global Classrooms (GC) when compared to traditional Model UN is the integrated issues and problem-based curriculum, skills development and support provided throughout an entire school year. Model $\mathrm{UN}$, on the other hand, is most often a one-time simulation of the United Nations. Additionally while Model UN is often available only to more privileged schools and communities, Global Classrooms is designed for schools and students who don't always have access to great resources.

Global Classrooms is a program initiated by the United Nations Association some 12 years ago to facilitate the integration of Model United Nations and Global Classrooms skills based curriculum into schools that had not experienced traditional Model UN. The idea is to support each portion of the program in more socioeconomically deprived schools, generally in urban areas. Primary goals of Global Classrooms include developing global / international knowledge based on global issues and countries, developing a variety of life skills leading to active global citizenship, and developing dispositions focusing on awareness and appreciation of multiple perspectives.

Global Classrooms has a constructivist-oriented curriculum based on several themes. The themes include peacekeeping, human rights, sustainable development, and globalization. Within each curriculum framework there are lessons that focus on developing a United Nations knowledge base and a general awareness of global issues. In addition, each lesson focuses on skills development including research, writing, collaboration, debate, and general public speaking. Dispositions encouraged through the curriculum include tolerance, awareness, collaborative demeanor, openness, and appreciation of difference.

A variety of thematic simulations are included to prepare students for the role-playing experience of Model UN (MUN). In addition, the curriculum is generic enough to encourage contextual adaptation to localize issues and even include less controversial simulations such as debating which type of candy is best, or the best fast food restaurants. Resources, lessons, and links are also included to support teaching and learning.

The program was initially supported through large grants that paid for the curriculum, professional development, the MUN conference, and support staff. Local United Nations Associations (UNA) generally served as the liaison between the UNA-USA in New York, local schools, and a Global Classrooms consultant. At present, most local Global Classrooms programs receive minimal funding from UNA-USA, although curriculum is still free. Staff members are paid minimally, if at all, and there is a charge to participate in the conference now. The charge covers the venue, lunches, some staff per diem, and basic conference support. Regardless of the sharp drop in funding support, the program is sustainable and has grown to several US and international cities.

Houston is one of the original cities supported by the UNA-USA and has been in existence since Fall 2001. Initially mandated that GC Houston only be available to Houston ISD, it expanded into Aldine ISD first and is now in several local districts and charter schools. Generally, over 3,000 students engage in some form of Global Classrooms during the school year, with 500 students participating in the culminating Global Classrooms; Model United Nations Conference held at the University of Houston each spring. 
Houston was initially quite unique in that it was one of the first programs to have both a middle school and high school Global Classrooms project as local schools recognized a need to integrate the program in $6^{\text {th }}$ grade world cultures classes which focused on the $20^{\text {th }}$ century, as well as various high school subjects. Houston schools also integrated the curriculum in a variety of ways within the specific social studies class itself, in clubs, and in stand alone elective courses. Even within each of these, individual teachers were able to adapt the curriculum in a variety of ways - as a current events / issues-based integration, as a way to develop life skills in clubs such as debate or speech, or as semester or year long Global Classrooms course integrating various components of the curriculum.

GC Houston holds several professional development sessions each year, focusing on introduction to Global Classrooms and Model UN, curriculum integration, conducting Model UN simulations, and conference preparation. Fall is typically used for curriculum integration, mock simulations and knowledge and skills development for the students. Spring is dedicated to conference preparation. Schools are assigned countries and topics depending on requests and numbers of students attending the conference. During the culminating conference 6 committees are usually represented at both the middle school and high school levels including Security Council and other committees of high interest such as UNICEF.

Students are assigned countries, research their countries, assigned committees, research their committees, then they are assigned topics, research the topics, articulate what their country's position is, then develop a position paper to assist with debate during the conference. Students engage in mock simulation to prepare for the conference, usually focusing on localized issues. Ultimately students are asked to role play UN ambassadors from their assigned countries. GC Houston has adapted the curriculum in a number of ways, but localized themes include energy, transportation, pollution, development, space issues, trade, education, and socio-economic issues - focusing on contextualized issues in Houston.

As a 12-year critical qualitative longitudinal study triangulation efforts included individual and focus group interviews, observations, and document analysis. The focus was on program implementation, effect on current practice, and attitudes toward alternatives curriculum and instruction. Educators generally suggested that the knowledge, skills, and dispositions enhanced through the program provide context and connections that are unique and often extend beyond the traditional approaches. Issues include the scripted imposition of curriculum, testing, and challenge to global education. Teachers nevertheless, expressed person professional growth and commented regarding student growth in global perspectives and awareness.

Despite the general success of Global Classrooms Houston, the program is challenged in local schools and districts and in Texas for addressing controversial issues, allowing for multiple perspectives, and not fitting into the Texas Essential Knowledge and Skills. Much of this is addressed by inviting critics to visit classrooms, observe student activities, and attend the culminating Model UN conference. Stakeholders generally agree that Global
Classrooms provides a contextualized global education missing from the current traditional curriculum. The largest ongoing issue is time, as teachers are increasingly subjected to scripted curriculum, benchmark testing, and formalized standardized testing, and narrow perceptions regarding achievement and accountability.

\section{Internationalizing a Department}

The university and city we are in are excellent examples the most internationally diverse in the country, and both also have strong international links. Our department has allowed our past international links dwindle, primarily due to impositions from college leadership (differing agendas). Student $\mathrm{s}$ and faculty increasingly found that global and international connections into education served as the "missing link" many needed to see the bigger picture of teaching and service to humanity. Many faculty and students knew that something was missing in their education; they just could not identify what it was. That missing link was a commitment to something greater than oneself in education. Critical qualitative research empowers educators to investigate issues tied to social education, thus enabling better global connections, possible sparks that enhance humanity individual and collective responsibility.

Research confirms the value of collaboration in all levels of education (Kincheloe, 2005; McLaren, 2006; Spring, 2003). The intention was to document the stories and process of internationalizing efforts in the department. Throughout the project, we documented the conversations among the faculty involved. Research assistants attended meetings to document conversations both hand-written and audio recording. We used documentation from these collaborative meetings to assess the impact of such partnerships on the research integration. Faculty members maintained reflective journals to record the challenges and successes encountered when incorporating the research projects. We believe the journals and conversations provided intimate insights into our growth as educators and the implementation of research projects. We will produce a summative brief that outlines challenges and successes that emerged throughout the semester.

Faculty members and their students completed pre- and post-course surveys. These surveys assessed participants' understanding culture, global connections, diversity, and change tied to allowing for multiple perspectives. In order to take advantage of the diverse backgrounds of our students we emphasize the rich qualitative data that emerges from the surveys. We will produce an analytical brief that summarizes results of the surveys.

Additional data was obtained from student work products collected through their coursework, including journals, comparative papers, and reviews of literature. Before engaging in international projects, faculty and students developed research questions to aid them in determining types of data to collect. These initial research questions along with the collected data, conclusion and recommendations for future action were collected in the form of end of course projects. Data collected on the challenges and success of the research projects will be summarized in the paper. 
A preliminary look at the transcripts of the task force meetings and the journals shows several interesting issues. The first was agreeing to specific directions regarding internationalization, particularly given all else that is imposed in teaching and learning. One educator lamented that increased standardization, and focus on benchmarks and testing allows little time for global connections in any curriculum. Faculty and students initially struggled with linking urban education issues with international or comparative education. All participants initially focused on their own narrow content and pedagogical agenda. Task force meetings and model courses that integrated an international focus provided support and encouragement for educators to allow for increased internationalization.

A second ongoing issue was the varied ways in which we conceptualize research and which pieces of research practice are the most important. None of the undergraduate courses in the study are research-based courses. One teacher educator struggled with "how far afield we should go from the goal of our courses, which does not include methodology.” Additionally, the students do not have experience with research methodology. Our team felt a great deal of pressure to teach methodology and create meaningful research projects but in an abbreviated, student friendly format. What constituted that abbreviated format was a focus of a great deal of discussion.

In our initial discussions of the student created action research projects we failed to consider the implications for students who had negative experiences. A teacher educator noted, "those students who observed or taught with teachers which the students felt were poor examples had a great deal of difficulty completing the research and formulating an alternative in which the students had a high level of confidence.” Students are eager to get into the field and were disappointed by experiences which they view as non-learning experiences. These "bad experiences" lead to discussions among team members over how much we can and should control the environments in which students' research.

For those students with positive experiences the action research project allowed them to take a systematic look at teaching practices. Many students considered the impacts of classroom management practices on the ability of teachers to engage students. Whether it was the lack of posting classroom rules, the cancelation of recess or breakfast service in the classroom to allow for extended instructional time, the student recognized that in order for students to be engaged in learn their basic needs must be met. In other instances, students critiqued questioning strategies and lesson plan formats for their ability to engage students and provide more in depth learning.

In the ongoing discussion of what education will need to prepare educators and students for life in the $21^{\text {st }}$ century, improved internationalization represents a framework for guiding that learning. Understanding the implications of these types of frameworks for educators at all levels is an important area of research. Additionally, in the continuing effort to build link global issues with current curriculum standards, action research should be situated as an integral practice of teaching. Action research modes of learning can benefit teachers at all levels as they pursue a reflective empowering examination of their practice. Through collaborative effort and a thoughtful dissection of one approach to integrating action research our paper advances the community and global aspect of education that are necessary for educators and students to become successful citizens of the world, and to pass those ideals along to their own students.

Increased globalization necessitates a more broad exploration of education. Internationalizing education through exchanges, research projects, courses, field experiences, and university partnerships can only enhance teacher education and facilitate global understanding and appreciation of multiple perspectives beyond education. International partnerships among interested parties including universities, schools and government agencies can only enhance future possibilities.

\section{China as a Case Study}

Social education at the university has had an international focus at least since 1995, with various projects in Indonesia, Japan, and New Zealand for example. This changed somewhat in 2007, when the social education program initiated global and international education courses and linked to the China abroad program for a month-long trip to China. The goals of the China experience included internationalizing the social education program area more extensively and eventually the department, facilitating possible future collaborations in China, and applying the experience towards our teaching and scholarship, again focusing on issues of social justice in a local to global context. The length of the experience helped facilitate better understanding of Chinese education and culture, and possible future endeavors lining our university with China.

Specific themes and issues emerged allowing for further critical investigation. After the on-site study in China and critical inquiry and reflection, White, Marsh, Mulholland and Thomas (2008), all social studies educators, began to question the traditional approaches to cultural studies by raising the question "how should culture be taught and subsequently learned” (p. 27). The everyday occurrences, some of which, though may be beyond their comfort zone, had the potential to revolutionize their beliefs and ways of being. Based upon the self-examination of their own biases and misunderstandings of culture, they called for a new mode of teaching and learning cultural studies that deconstruct "the historical layers of structural bias and self-serving functionality” (p. 31).

Three years later, in the summer of 2010, another cohort of educators embarked on the trip to China. They were students and faculty from the new executive Ed. D. (Executive Education Doctorate) program of our college of education. The new Ed. D. program was launched in 2009, which encompasses a two-year (51 hours) cohort program where students investigate urban school issues in a lab of practice leading to their dissertation. In response to the growing impact of global challenges on educational leaders, the program offered an international trip to allow students an opportunity to obtain a first-hand experience of diverse educational systems and cultures. China was chosen for the first international focus due to the current college projects in China and the current globalization focus on China. The final synthesis project after the trip 
helped them establish a holistic and profound understanding of their new learning and experience, and in the culminating presentation attended by all the students and Ed. D. program faculty, they presented and shared how this cross-cultural experience impacted not only their philosophies and practices as educational leaders, but also their doctoral research and personal life.

We made individual and group interviews with the Ed. D. students, and examined documents, field notes, interview transcripts, student journals, online discussion postings and other course projects including review of literature and comparative paper. They were also invited to complete pre-and post-course surveys tied to the China experience. These surveys assessed participants' understandings of culture, global connections, diversity and changes in these perceptions. In order to take advantage of the diverse backgrounds of our students, we emphasized the rich qualitative data that emerge from the surveys.

All in all, China's experience has affected the students personally and professionally, which was echoed repeatedly in the conversations and interviews with them, their journals, online discussions, papers and final presentation. Personally, they have become willing or more willing to critically look at the stereotypes previously hidden in their minds, or preconceived notions prevalent in the media; they have learned to recognize and appreciate differences, abandon the search for one correct answer, and become more open and receptive to different perspectives; they have learned to seek out and evaluate information from diverse sources and approach new information with an open mind.

Professionally, the two-week immersion into crosscultural context has not only helped the students learn the society, culture and education of China, but also provided them with an opportunity to reflect upon social, cultural and educational issues in America. Most of them have gained a deeper awareness that they could impact the world and national issues beyond immediate surroundings through their work with school administration. With a refined understanding of international education and global issues, many of them have expressed their desires to share their new learning and experience with their staff, teachers, students and community at large.

During the stay in China, we, as the director and research assistant of "Internationalizing Education Task Force" of the department, bore another mission: establishing partnerships with Chinese universities and negotiating potential collaboration possibilities. Drawing upon the existing proposal of “Joint Master's of Education Degree” of Department of Curriculum and Instruction directed to Vietnamese universities, we worked out a proposal targeted at Chinese universities. It consists of 12 graduate courses, including three college core courses, six courses in a specific program area (five program areas available for students to choose from) and three electives. It is a one-plus-one program by offering half of the courses in China and the other half in the University of Houston in the U.S. We believe that this joint degree program, built upon the major strengths in each institution, will be mutually beneficial: As a result of the project, the prospective educators from China will develop a better understanding of American education, culture and society, and the American peers and faculty can broader their eyes through the new learning and teaching experiences, and see things through a broader perspective coming from their Chinese counterparts.

As a result, 2 cohorts of Chinese educators have now participated in the $1+1 \mathrm{MEd}$ program. In the ongoing discussion of what educators will need to be prepared for life in the 21st century, improved internationalization represents a framework for guiding that learning. We have already seen the improved knowledge, skills, and disposition a globally interdependent world requires among our participants by engaging in kinds of international undertakings, which have the potential to be a profoundly life-changing experience. We will be seeking to collaborate with more overseas educators, share our experience of internationalizing education, understand each other's contexts and concerns, and support each other's initiatives for the common goal of preparing globally minded educators.

We believe that as our tie to China's educational colleagues gets closer and closer, the endeavors of internationalizing education will obtain more momentums than ever before. Meanwhile, we are aware that much work needs to be done on the part of educators, if internationalization is going to become reality, and that work cannot be accomplished by individuals in isolation. It is hoped that this article can serve as an impetus to not only further our individual efforts, but also call for more commitment to the undertaking of internationalizing education.

\section{Conclusion}

We live in a world made up of many texts; it is essential that students and educators develop multiple literacies that will facilitate the reading of signs, symbols, and images (texts) of that world. We must develop the critical capacity for “new operational and cultural 'knowledge' in order to acquire a global perspective that provides access to new forms of work, civic and private practices in their everyday lives” (Lankshear \& Knoble, 2003). Our educational approaches could be the place to enable the critical investigation of meaningful knowledge and issues, debates regarding globalization, and relevant problembased global education that can provide the context for developing the skills engage in active transformation for social justice. "Reading the world" through context and relevant connections provides the opportunity to apply knowledge and develop skills in critical ways, as Kincheloe (2005) recommends. Responsible global citizenship requires knowledge of "others" in the world, whoever they might be. It also requires the skills to understand and act in the best interest of the majority of the people. The knowledge base should include an understanding of who the other people in the world are, what they do, and where they are. The skill set should include inquiry and critical literacy/thinking skills, leading to activism

Increased globalization not only presents many challenges to the economy, society, politics and culture, but also has important implications for education, and the institution of education has the responsibility for addressing these issues. However, there is an increasing concern that educational systems throughout the world are 
not adequately preparing students for understanding of the world's cultures, economies and political relationships (Asia Society, 2001). Educators and students should develop the habit of thinking of global ramifications: Is this in the common good? Will this protect the rights of all people (Merryfield \& Wilson, 2005)? To create a positive atmosphere, in which students are encouraged to participate in global discourse and engage in global issues in today's multicultural society, educators need to, first of all, develop multiple perspectives and understand the experiences and points of view of people different from themselves. Meaningful international education projects can help educators achieve that (Wells, 2008). As James (2005) suggested, internationalizing education can develop a sense of interconnectedness, empathy and tolerance, which are much needed in today's world. However, though there have been some initiatives of internationalizing teacher education exemplified by the institutions, such as Ohio State University and Stanford University (Roberts, 2007), the undertaking is yet to be given due credits, as it deserves nationwide.

"Humans are storytelling organisms who, individually and socially, lead storied lives. The study of narrative and other qualitative approaches, therefore, is the study of the ways humans experience the world” (Connelly \& Clandinin, 1990, p. 2). The fundamental idea of critical inquiry in social education is that education is life and experience as well. Therefore, education and critical qualitative educational research are the construction and reconstruction of personal and social stories of teachers, as well as other strategies in which learners and researchers engage within an equity and social justice framing, for the betterment of society. Accordingly, the responsibility of critical researchers of education is to investigate the hard questions, to critically analyze issues and to suggest alternatives, and to render their experiences in meaningful ways so as to challenge issues of power and privilege

\section{References}

[1] Apple. M. (1990). Ideology and curriculum. New York: Routledge.

[2] Asia Society. (2001). Asia in the schools: Preparing young Americans for today's interconnected world. National Commission on Asia in the Schools Report, International ED. org.

[3] Chapin, J. (2003). A practical guide to secondary social studies. Boston: Pearson Education.

[4] Connelly, F. M., \& Clandinin, D. J. (1990). Stories of experience and narrative inquiry. Educational Researcher, 19(5), 2-14.

[5] Dan-xia, C. (2008). A social distance study of American participants in a China study program. US - China Education Review. 5(9), 17-22.

[6] Diaz, C., B. Massialas, and J. Xanthopoulos. (1999). Global perspectives for educators. Boston: Allyn \& Bacon.

[7] Freire, P. (1970). Pedagogy of the oppressed. New York: Herder and Herder.

[8] Gay, G. (2010). Culturally responsive teaching. New York: Teachers College Press.

[9] Goodman, G., Ullrich, W., and Nana, P. (2012). Action research for critical classroom and community change. (pp. 390 - 407). In Steinberg, S. and Cannella, G. (eds.) Critical qualitative research reader. New York: Peter Lang.

[10] Giroux, H. (2004). Public pedagogy and the politics of neoliberalism. Policy Futures in Education. 2 (3/4), 494-503.
[11] Herr, K., and Anderson, G.L. (2005). The action research dissertation: A guide for students and faculty. Thousand Oaks, California: Sage Publications.

[12] Hickey, A. (2012). The critical aesthetic. (pp. 166 - 181). In Steinberg, S. and Cannella, G. (eds.) Critical qualitative research reader. New York: Peter Lang.

[13] hooks, B. (1994). Teaching to transgress. New York: Routledge.

[14] James, K. (2005). International education. Journal of Research in International Education, 4, 313-332.

[15] Johnston, M. (2006). The lamp and the mirror: Action research and self studies in the social studies. In K. C. Barton (Ed.), Research methods in social studies education: Contemporary issues and perspectives (pp. 57-83). Greenwich, CT: Information Age Publishing.

[16] Kincheloe, J. (2005). Getting beyond the facts. New York, NY: Peter Lang.

[17] Kincheloe, J. (2005). On to the next level...Qualitative Inquiry. 11, 323-350.

[18] Kincheloe, L. (2008). Critical pedagogy. New York: Peter lang.

[19] Kincheloe, J, McLaren, P, and Steinberg, S. (2012) Critical pedagogy and qualitative research. In Steinberg, S. and Cannella, G. (eds.) Critical qualitative research reader. (pp. 14-32). New York: Peter Lang.

[20] LaBoskey, V. K. (2004). The methodology of self-study and its theorrectical underpinnings. In J. J. Loughran, M. L. Hamilton, V. L. LaBoskey, \& T. Rusell (Eds.), International handbook of selfstudy of teaching and teacher education practices (pp. 817-870). Dordrecht: Kluwer.

[21] Loewen, J. (2007). Lies my teacher told me. New York, NY: Touchstone.

[22] Loughran, J. (2005). Researching teaching about teaching: Selfstudy of teacher education practices. Studying Teacher Education, 1 (1), 5-16.

[23] McLaren, P. (2006). Life in schools. New York, NY: Allyn and Bacon.

[24] Merryfield, M. M., \& Wilson, A. (2005). Social studies and the world. Silver Spring, M. D.: National Council for the Social Studies.

[25] Merryfield, M. (2008). Scaffolding social studies for global awareness. Social Education. 72 (7).

[26] Ochoa-Becker, A. (2006). Democratic education for social studies. Charlotte, NC: Information Age Publishing.

[27] Roberts, A. (2007). Global dimensions of schooling: Implications for internationalizing teacher education. Teacher Education Quarterly, 34(1), 9-26.

[28] Ross, E. W. (2006). The social studies curriculum. Albany, NY: SUNY Press.

[29] Samaras, A. P., \& Freese, A. R. (2006). Self-study of teaching practices. New York, NY: Pete Lang Publishing, Inc.

[30] Spring, J. (2003). American education. New York, NY: McGraw Hill.

[31] Steinberg, S. (2011). Critical cultural studies research. In K. Tobin and J. Kincheloe (eds). Doing educational research. Rotterdam; Sense Publishing.

[32] Steinberg, S. and Cannella, G. eds. (2012). Critical qualitative research reader. New Yor: Peter Lang.

[33] Tucker, J. and A. Evans. (1996). The challenge of a global age. In Crucial issues in teaching social studies K-12, ed. B. Massialas and R. Allen, 181-218. Belmont CA: Wadsworth Publishing.

[34] Wells, R. (2008). The global and multicultural: Opportunities, challenges, and suggestions for teacher education. Multicultural Perspectives. 10(3), 142-149.

[35] White. C. and Walker, T. (2008). Tooning in: Essays on popular culture and education. New York: Rowan and Littlefield.

[36] White, C., Marsh, S., Mulholland, A., \& Thomas, D. (2008). Rethinking the learning of "culture": A Chinese inquiry. US-China Education Review, 5(5), 27-31.

[37] Zeichner, K. (2009). Teacher education and the struggle for social justice. New York: Routledge.

[38] Zinn, H. (2005). A people's history of the United States. New York: Harper Classics. 